\title{
Predicting the capability of carboxylated cellulose nanowhiskers for the remediation of copper from water using response surface methodology (RSM) and artificial neural network (ANN) models
}

\author{
Hazren A. Hamid ${ }^{\text {a }}$, Youla Jenidi ${ }^{\text {a, b }}$, Wim Thielemans ${ }^{c}$, Christopher Somerfield ${ }^{d}$, \\ Rachel L Gomes ${ }^{a, *}$ \\ ${ }^{a}$ Bioprocess, Environmental and Chemical Technologies Research Group, Faculty of \\ Engineering, University of Nottingham, University Park, Nottingham, NG7 2RD, \\ United Kingdom. \\ ${ }^{\mathrm{b}}$ AECOM, Belvedere House, Pynes Hill, Exeter, EX2 5WS, United Kingdom \\ ${ }^{c}$ Renewable Materials and Nanotechnology Research Group, KU Leuven Campus \\ Kulak Kortrijk, Etienne Sabbelaan 53, 8500 Kortrijk, Belgium. \\ ${ }^{\mathrm{d}}$ Fluids and Thermal Engineering Research Group, Faculty of Engineering, University \\ of Nottingham, University Park, Nottingham, NG7 2RD, United Kingdom. \\ *Corresponding author. E-mail address: rachel.gomes@nottingham.ac.uk
}

\begin{abstract}
This study observed the influence of temperature, initial $\mathrm{Cu}(\mathrm{II})$ ion concentration, and sorbent dosage on the $\mathrm{Cu}(\mathrm{II})$ removal from the water matrix using surface-oxidized cellulose nanowhiskers (CNWs) bearing carboxylate functionalities. In addition, this study focused on the actual conditions in a wastewater treatment plant. Conductometric titration of CNWs suspensions showed a surface charge of 54 and $410 \mathrm{mmol} / \mathrm{kg}$ for the unmodified and modified CNWs, respectively, which indicated that the modified CNWs provide a relatively high surface area per unit mass than the unmodified CNWs. In addition, the stability of the modified CNWs was tested under different conditions and proved that the functional groups were permanent and not degraded. Response surface methodology (RSM) and artificial neural network (ANN) models were employed in order to optimize the system and to create a predictive model to evaluate the $\mathrm{Cu}$ (II) removal performance of the modified CNWs. The performance of the ANN and RSM models were statistically evaluated in terms of the coefficient of determination $\left(R^{2}\right)$,
\end{abstract}


absolute average deviation (AAD), and the root mean squared error (RMSE) on predicted experiment outcomes. Moreover, to confirm the model suitability, unseen experiments were conducted for 14 new trials not belonging to the training data set and located both inside and outside of the training set boundaries. Result showed that the ANN model $\left(\mathrm{R}^{2}=0.9925, \mathrm{AAD}=1.15 \%, \mathrm{RMSE}=1.66\right)$ outperformed the $\mathrm{RSM}$ model $\left(\mathrm{R}^{2}=0.9541, \mathrm{AAD}=7.07 \%, \mathrm{RMSE}=3.99\right)$ in terms of the $\mathrm{R}^{2}, \mathrm{AAD}$, and RMSE when predicting the $\mathrm{Cu}$ (II) removal and is thus more reliable. The Langmuir and Freundlich isotherm models were applied to the equilibrium data and the results revealed that Langmuir isotherm $\left(\mathrm{R}^{2}=0.9998\right)$ had better correlation than the Freundlich isotherm $\left(\mathrm{R}^{2}=0.9461\right)$. Experimental data were also tested in terms of kinetics studies using pseudo-first order and pseudo-second order kinetic models. The results showed that the pseudo-second-order model accurately described the kinetics of adsorption.

Keywords: Artificial neural networks; Adsorption; $\mathrm{Cu}(\mathrm{II})$ ions; Cellulose nanowhiskers; Response surface methodology 


\section{Introduction}

The amount of heavy metals released into the aqueous environment has been increasing as a result of anthropogenic activities such as mining, sludge disposal, and electroplating, with the effects of these metals on the ecosystem causing global concern (Shojaeimehr et al., 2014; Svecova et al., 2006; Wang et al., 2013). Adsorption offers an alternative to the remediation of industrial and municipal wastewater effluent as conventional technologies such as ion exchange, reverse osmosis, filtration, electrochemical treatment, and membrane technologies are expensive and generate large amounts of sludge waste (O'Connell et al., 2008b). The adsorption process is very effective and simple compared to other treatments, especially in removing low concentrations of heavy metals from the water matrix (Ashraf et al., 2011). Removal of these pollutants by an adsorption process also offers the opportunity to consider waste as a resource and recover the heavy metals for reuse by regenerating the adsorbent.

The development of adsorption technology is for a large part focussed on the development of the most efficient adsorbent. Cellulose is one such adsorbent that has been investigated for the adsorption of heavy metal ions (Isobe et al., 2013; O'Connell et al., 2008a). Cellulose is the most abundant natural, renewable, and biodegradable polymer and as a raw material is available at relatively low cost for the preparation of various functional polymers (O'Connell et al., 2008a). Chemical modification of cellulose by grafting of functional groups has the potential to improve its adsorption capacity and to enhance its performance under desired conditions. Carboxylic acid groups are one example of a functional group that can be introduced onto the cellulose surface by (TEMPO)-mediated oxidation and this oxidized cellulose adsorbent has been shown to be capable of adsorbing $465.1 \mathrm{mg} / \mathrm{g} \mathrm{Pb}$ (II) from aqueous solution ( $\mathrm{Yu}$ et al., 2013). However, only limited work has been published on using cellulose nanowhiskers (CNWs) as an adsorbent, as the majority of the literature has mainly focused on macroscopic lignocellulosic biomass such as jute, orange peel, wood sawdust, wood pulp and sugarcane bagasse fibres, rather than pure cellulose (Reddy, 2012). Although most of the adsorbents mentioned above are considered good adsorbents, CNWs offer higher adsorption capacity and performance due to high specific surface areas and a high reactive group density on the surface (Eyley and Thielemans, 2014). In addition to acting as an adsorbent, the cellulose-derived material has also showed potential as a 
support for a primary adsorbent (activated carbon) in wastewater treatment, or also served as a backbone structure upon which the main adsorbent is attached (Zhu et al., 2009) is a further example for the use of modified CNWs as an adsorbent to remove pollutants from water.

Besides (TEMPO)-mediated oxidation, the carboxyl functional groups can also be introduced through esterification, which may increase the amount of carboxylic acid functionalities on the cellulose surface, as secondary hydroxyl groups can also be converted to carboxylates, and thus the adsorption capacity of the modified adsorbent. For example, CNWs were chemically modified with succinic anhydride to obtained carboxylated CNWs. However, the reported modification process using succinic anhydride as an active agent was time consuming and not very sustainable as this process required $12 \mathrm{~h}$ under pyridine reflux in order to obtained the final modified adsorbent (Yu et al., 2013). Moreover, pyridine is a well known problem in the chemical industry and is avoided as much as possible as it may cause harmful health effects (U.S. Public Health Service, 1992). In addition, refluxing in pyridine, where pyridine vapour is generated is not considered sustainable (Xu et al., 2015).

In many studies, the range of the investigated parameters for the adsorption process is often not representative of the actual conditions in a wastewater treatment plant (WWTP) (Thirumavalavan et al., 2010). For example, the majority of the studies are performed with a high initial metal ion concentration $(100-1000 \mathrm{mg} / \mathrm{L})$ which is unrealistic for actual commercial adsorption processes as they are generally applied to low concentration streams. This is the case because the majority of the conventional technologies are impractical at treating heavy metal contamination at low concentration due to high operational and maintenance cost (Ashraf et al., 2011). Furthermore, most of the reported experiments are also conducted under unrealistic conditions to a wastewater treatment environment such as a relatively high temperature up to $45^{\circ} \mathrm{C}$, as too high temperature could accelerate decomposition of chelating efficiency, leading to the decrease of the adsorption ratio (Sahan et al., 2010). Moreover, a range of $\mathrm{pH}$ without considering the metal hydroxide precipitation will also effect the removal of $\mathrm{Cu}$ (II) from the water matrix (Thirumavalavan et al., 2010). Finally, the adsorbent dosage is an important parameter in the adsorption process as it will provide the 
required amount of sorbent dosage for a given initial concentration, thereby defining the separation cost and the total water treatment cost (Anupam et al., 2011).

As reported in the literature, studies tend to focus on one single parameter at a time. This will inherently require a longer time to determine the optimum adsorption conditions and is assumed as non-practical since parameter interactions cannot be elucidated using this approach (Turan et al., 2013). Thus, to overcome this difficulty, experimental factorial design can be employed to optimize the adsorption of $\mathrm{Cu}$ (II) from the water matrix (Zolgharnein et al., 2013). Among the various experimental designs, it was found that two common designs, central composite design (CCD) and BoxBehnken design (BBD), have been used frequently for the final optimization of desired processes (Turan et al., 2013; Zolgharnein et al., 2013). In this study, the CCD was selected because it has better predictive capabilities and it has been extensively applied in adsorption studies (Bingol et al., 2012; Shanmugaprakash and Sivakumar, 2013).

Response surface methodology (RSM) and artificial neural network (ANN) are models that are applied extensively in industry in the optimization of process design parameters. RSM is a practical method for studying the effect of multiple parameters or variables that influence the process response by varying them simultaneously and reducing the number of required experiments. Artificial neural networks (ANNs) are mathematical models that predict the output on the basis of input data without a clear relationship between them. Therefore, the utilization of ANNs in the field of adsorption processes by using biomass has recently gained interest, given the difficulty that can be encountered to fully characterize all the functionalities found in common biomass (Shojaeimehr et al., 2014). For example, ANNs have been successfully used to model the biosorption of $\mathrm{Pb}$ (II) using black cumin (Bingol et al., 2012), the removal of fluoride by bone char (Tovar Gomez et al., 2013), and the removal of $\mathrm{Cu}$ (II) using sunflower shells (Oguz and Ersoy, 2010). This approach has also been used for the study of adsorption of dyes and organic compounds (Witek-Krowiak et al., 2014). However, most of the previous literature focuses its attention on adsorption studies by using either RSM or ANN without comparing the performances. Furthermore, the testing of both RSM and ANN using new sets of experiments not belonging to the training data set, has only be undertaken by a limited number of studies on biomass adsorption and without consideration of how the additional experiments represent the system and gives a more 
accurate indicator of performance (Bingol et al., 2012; Ghosh et al., 2015). Therefore, model suitability for interpolated and extrapolated experimental parameters was tested, which is rare in the existing literature but provides valuable insights into applicability of the approaches tested in this work. Moreover, with the kinetics and isotherms studies, this study will offer better understanding regarding adsorption mechanisms and equilibrium behaviour of adsorbent.

The objective of this study was to build two models: RSM and ANN, and assess their abilities to determine the effectiveness of (TEMPO)-mediated oxidation cellulose nanowhiskers (CNWs) functionalized with carboxylate functionalities at removing copper ions from water. The first part of the study focused on the modification of CNWs through a controlled surface oxidation to improve the effectiveness of this adsorbent in removing $\mathrm{Cu}$ (II) from the water matrix. This study also focuses on the stability of the modified CNWs at different time intervals under dry conditions and in the water matrix. To the best knowledge of the authors, there are no papers that presently test the stability of this modified CNW under these conditions, relevant from both the manufacturing and application perspectives. Scoping experiments were then performed to identify the variables and parameter ranges that are able to provide as much information in order to help set the boundary conditions for the CCD. Next, both RSM and ANN models were employed to understand the obtained data and evaluate the predictive capability of each model for the effective $\mathrm{Cu}$ (II) removal from the water matrix. Moreover, unseen experiments that lie both inside and outside of the test parameter system were performed to test the model suitability. This is also novel as generally only a couple parameter variations are tested without checking the obtained model suitability for parameters lying in between the tested parameters, and certainly not for parameters lying outside the tested parameter space as is done in this work. 


\section{Materials and methods}

\subsection{Reagents}

All the chemical reagents used in these studies were analytical grade, including copper(II) sulphate pentahydrate $\left(\mathrm{CuSO}_{4} .5 \mathrm{H}_{2} \mathrm{O}\right)$ and $\mathrm{Cu}(\mathrm{II})$ atomic absorption spectrometry standard solution $(1000 \mathrm{mg} / \mathrm{L})$.

\subsection{Preparation of adsorbent}

\subsubsection{TEMPO-Mediated oxidation of cellulose}

Cellulose nanowhiskers (CNWs) were produced from bleached cotton by hydrolysis with a mass fraction of $64 \%$ sulphuric acid to produce a suspension of highly crystalline CNWs according to standard procedures (Labet and Thielemans, 2011). The resulting CNWs were then reacted with TEMPO, sodium bromide, and sodium hypochlorite for $45 \mathrm{~min}$ under constant stirring at room temperature $\left(\mathrm{T}=19^{\circ} \mathrm{C}\right)$ at $\mathrm{pH} 10$ to introduce the carboxyl groups onto the CNWs' surface followed by freeze-drying (Habibi et al., 2006).

\subsubsection{Characterization}

Infrared spectroscopy was used to determine functional group absorption bands in the modified CNWs on a Thermo-Nicolet 380 FTIR spectrometer (Thermo Fisher Scientific Inc., USA) in transmission mode. Two mg of the solid samples (CNWs) were milled with $200 \mathrm{mg}$ potassium bromide $(\mathrm{KBr})$ to form a very fine powder using agate pestle and mortar. This powder was then compressed to form a thin transparent disk at 10 metric tonnes pressure for FTIR analysis. Zeta potential of particles was measured with a Malvern Instrument Nano-ZS Zetasizer (Malvern Instrument Ltd., Worcestershire, UK). Five $\mathrm{mg}$ of the solid samples (CNWs) was diluted in $5 \mathrm{~mL}$ of deionised water and sonicated for $10 \mathrm{~min}$ before analysis.

\subsubsection{Determination of carboxylate groups}

The content of carboxyl group on the TEMPO-oxidized CNWs was determined by conductometric titration (Saito and Isogai, 2004). Approximately $0.1 \mathrm{~g}$ of freezedried CNWs was mixed with $49 \mathrm{~mL}$ of deionized water and $1 \mathrm{~mL}$ of $0.05 \mathrm{M}$ sodium chloride $(\mathrm{NaCl})$, and the mixture was stirred to obtain a well-dispersed solution. Then, the resulting suspension was titrated with $0.05 \mathrm{M}$ sodium hydroxide $(\mathrm{NaOH})$ solution at 
the rate of $0.1 \mathrm{~mL} / \mathrm{min}$ while stirring continuously and the solution conductivity was recorded by a conductivity meter (Model No: 9811, Hanna Instruments Ltd., UK). The titration was carried out three times for each sample, and the experimental errors were calculated as a standard deviation. The carboxyl content of the sample was determined from the conductometric titration curve and was calculated by Eq. (1), assuming that each added molecule of $\mathrm{NaOH}$ with this range neutralized exactly one carboxyl group and all other weak acidic groups (e.g. aldehyde groups) are oxidized to carboxyl groups during the oxidation reaction:

$$
X(m m o l / k g)=\frac{C_{t} V_{2}}{m}
$$

where $\mathrm{X}$ is the total amount of carboxyl groups ( $\mathrm{mmol} / \mathrm{kg}), \mathrm{C}_{\mathrm{t}}$ is the concentration of the sodium hydroxide $(\mathrm{mol} / \mathrm{L}), \mathrm{V}_{2}$ is the volume of the sodium hydroxide solution consumed at the $2^{\text {nd }}$ intersection point $(\mathrm{L})$, and $\mathrm{m}$ is the oven-dry weight of sample after titration (g) (Saito and Isogai, 2004).

\subsection{Preparation of $\mathrm{Cu}(\mathrm{II})$ stock solution}

$\mathrm{Cu}$ (II) stock solution of varying initial concentrations $(10-60 \mathrm{mg} / \mathrm{L})$ was prepared in different volumetric flask by dissolving the appropriate amount of $\mathrm{CuSO}_{4} \cdot 5 \mathrm{H}_{2} \mathrm{O}$ in Milli-Q Ultrapure water.

\subsection{Determination of the $\mathrm{Cu}(\mathrm{II})$ in the solutions}

The initial and final concentration of $\mathrm{Cu}(\mathrm{II})$ in the solutions was determined by flame atomic absorption spectrometry (AAS) (Model No: 272, PerkinElmer Inc., USA). The hollow cathode lamp was operated at $10 \mathrm{~mA}$ and the analytical wavelength was set at $324.8 \mathrm{~nm}$.

The standard solutions (10-70 $\mathrm{mg} / \mathrm{L})$ that span the working ranges were prepared by using the provided $1000 \mathrm{mg} / \mathrm{L}$ reference standard solution (ROMIL Ltd) for $\mathrm{Cu}$ (II) with Milli-Q water. The absorbance of a sample was measured and the concentration was calculated from the calibration curve that was determined by the prepared standard solutions of $\mathrm{Cu}$ (II). A linear regression curve $(y=0.00488 x-0.00083)$ was obtained in the $\mathrm{Cu}(\mathrm{II})$ concentration range from 10 to $70 \mathrm{mg} / \mathrm{L}$ with a correlation coefficient of 0.999 . 
The percentage of the removal $\mathrm{Cu}$ (II) ions by the sorbent and the adsorption capacity $(\mathrm{mg} \mathrm{Cu}(\mathrm{II}) / \mathrm{g})$ were expressed by:

$$
\begin{gathered}
\text { \% removal }=\frac{C_{o}-C_{e}}{C_{o}} \times 100 \\
q_{e}=\left(\frac{\left(C_{o}-C_{e}\right) V}{W}\right)
\end{gathered}
$$

Where $\mathrm{C}_{\mathrm{o}}(\mathrm{mg} / \mathrm{L})$ is the initial $\mathrm{Cu}(\mathrm{II})$ concentration and $\mathrm{C}_{\mathrm{e}}(\mathrm{mg} / \mathrm{L})$ is the equilibrium $\mathrm{Cu}$ (II) concentration in solution, $\mathrm{V}$ is the volume of the solution (L), and $\mathrm{W}$ is the mass of adsorbent (g) (Ghosh et al., 2015).

\subsection{Batch adsorption experiments}

Batch experiments were performed in $100 \mathrm{~mL}$ conical flasks, in an incubator (Model No: 120, LMS Ltd., Kent, UK), with temperature control and agitation (150 rpm) using a mini table shaker (IKA Vibrax VXR, Germany). The contact time (30 min), and the initial $\mathrm{pH}(\mathrm{pH}$ 6.0) were selected on the basis of the results obtained from scoping experiments. The required weight of sorbent $(0.2-10.0 \mathrm{~g} / \mathrm{L})$ was measured separately into the $100 \mathrm{~mL}$ conical flask, and then $20 \mathrm{~mL}$ of $\mathrm{Cu}$ (II) solution with the known concentration (10-60 mg/L) were added into the flasks. The initial $\mathrm{pH}$ of the solution was adjusted with $1 \mathrm{M} \mathrm{H}_{2} \mathrm{SO}_{4}$ and $1 \mathrm{M} \mathrm{NaOH}$ at 6 , using the $\mathrm{pH}$ meter (Hanna Instruments Ltd., UK), calibrated with buffers of $\mathrm{pH} 4.0,7.0$, and 10.0 in order to maintain constant $\mathrm{pH}$ throughout the experiment. Next, the initial $\mathrm{Cu}(\mathrm{II})$ concentration and the final concentration after adsorption process were separated from the sorbent using $0.2 \mu \mathrm{m}$ surfactant-free cellulose acetate membrane syringe filter and were determined using AAS.

\subsection{Experimental design}

The temperature, initial $\mathrm{Cu}(\mathrm{II})$ ion concentration, and sorbent dosage were used as independent (input) variables and were studied for their impact on the removal of $\mathrm{Cu}$ (II) from the water matrix. These parameters and their range were selected based on the literature (Cao et al., 2014; Thirumavalavan et al., 2010) and scoping studies undertaken 
in this study. Fixed conditions for $\mathrm{pH}$ and time were chosen to be 6 and $30 \mathrm{~min}$ respectively as determined in the scoping studies.

The investigated temperature range was $6^{\circ} \mathrm{C}-25^{\circ} \mathrm{C}$ in order to study the efficiency of the CNWs as adsorbents at different temperatures. This range of temperatures is a realistic range in the wastewater treatment environment where the mean annual temperature of wastewater varies from 10 to $25^{\circ} \mathrm{C}$ (Burton et al., 2013). Moreover, another example is the study conducted by Hanaki (2008), who showed that the wastewater range is $15-25^{\circ} \mathrm{C}$ (Hanaki, 2008).

Since the majority of conventional technologies are impractical for treating heavy metal at low concentrations due to high operating cost (Gavrilescu, 2004), the range for the initial $\mathrm{Cu}(\mathrm{II})$ ion solution was chosen to be $10-60 \mathrm{mg} / \mathrm{L}$. Thus, the temperature (6$\left.25^{\circ} \mathrm{C}\right)$, initial $\mathrm{Cu}(\mathrm{II})$ ion concentration $(10-60 \mathrm{mg} / \mathrm{L})$, and sorbent dosage $(0.2-10 \mathrm{~g} / \mathrm{L})$ were investigated for their effect on the removal efficiency of $\mathrm{Cu}(\mathrm{II})$ from the water matrix.

\subsubsection{Response surface methodology}

$\mathrm{RSM}$ is an approach that combines mathematical and statistical techniques and can be applied to give a better overall understanding with a minimal number of experiments. Optimization studies were carried out by studying the effect of three variables, i.e. temperature, initial $\mathrm{Cu}(\mathrm{II})$ ion concentration, and sorbent dosage. With these three variables, a total of 20 experiments were required in order to find the optimum operating condition for the removal of $\mathrm{Cu}$ (II) using modified $\mathrm{CNW}$. The experimental data was processed using Minitab 16 Statistical Software. The parameters are shown in reverse with their coded levels $(-\alpha,-1,0,1, \alpha ; \alpha=1.633)$, respectively. The value of $\alpha$, which depends on the number of factors, is chosen to maintain rotatability, which refers to the uniformity of the prediction error. The predicted percentage of the removal $\mathrm{Cu}(\mathrm{II})$ ions is explained by the following quadratic equation:

$$
Y(\%)=\beta_{0}+\sum_{i=1}^{k} \beta_{i} x_{i}+\sum_{i=1}^{k} \beta_{i i} x_{i}^{2}+\sum_{i<j} \sum \beta_{i j} x_{i} x_{j}+\varepsilon
$$


Where $Y$ is the predicted response, $x_{i}$ and $x_{j}$ are the input variables, $\beta_{o}$ is the intercept term, $\beta_{\mathrm{i}}$ is the coefficient of linear effect, $\beta \mathrm{ii}$ is the coefficient of squared effect, $\beta_{\mathrm{ij}}$ is the coefficient of interaction effect and $\varepsilon$ is a random error.

\subsection{Artificial neural network}

ANN is a powerful tool and has been widely used to model the effect of parameters influencing adsorption processes (Shanmugaprakash and Sivakumar, 2013). This is due to their capability in solving the non-linear functional relationship between several parameters and variables involved in the process under study. The ability of ANN to learn and capture the behaviour of any complex and non-linear process makes it a potential modelling tool. On the other hand, RSM uses quantitative data in an experimental design to search for the optimum conditions. For a better accuracy, the experimental responses to design of experiments (DOEs) are fitted to a quadratic equation.

Although there are many well-known ANN types such as multilayer perceptron, radial basis function networks, linear networks, Bayesian networks, and Kohonen networks, currently the most popular network architecture is multilayer perceptron (MLP) (Savic et al., 2012) . One of the common structures of an artificial network consists of three different layers: inputs, hidden layer and outputs layer and is commonly applied in the prediction of the performance of many processes (Pilkington et al., 2014; Witek-Krowiak et al., 2014). In order to use the ANN model for predicting $\mathrm{Cu}$ (II) removal from the water matrix, a feed-forward backpropagation algorithm was used for modelling the experimental design. The ANN was built in MATLAB (Figure 1) with three input neurons indicating the temperature, initial $\mathrm{Cu}(\mathrm{II})$ concentration and sorbent dosage, a single hidden layer of neurons, and an output neuron indicating the percentage of $\mathrm{Cu}(\mathrm{II})$ removal. Three input neurons are connected to the hidden neurons, which represent nonlinear activation functions that transform the inputs into something the output layer can utilise. The single hidden layer with a tangent sigmoid transfer function (tansig), required a minimum of 6 hidden neurons for the simulation and prediction of $\mathrm{Cu}(\mathrm{II})$ removal.

In this study, the first layer of neurons representing the independent variables were identical to the factors considered in RSM approach, namely temperature (6- 
$\left.25^{\circ} \mathrm{C}\right)$, initial $\mathrm{Cu}(\mathrm{II})$ ion concentration $(10-60 \mathrm{mg} / \mathrm{L})$, and sorbent dosage $(0.2-10 \mathrm{~g} / \mathrm{L})$. Similar to the RSM model, the outputs represented the percentage removal of $\mathrm{Cu}(\mathrm{II})$ under the investigated conditions.

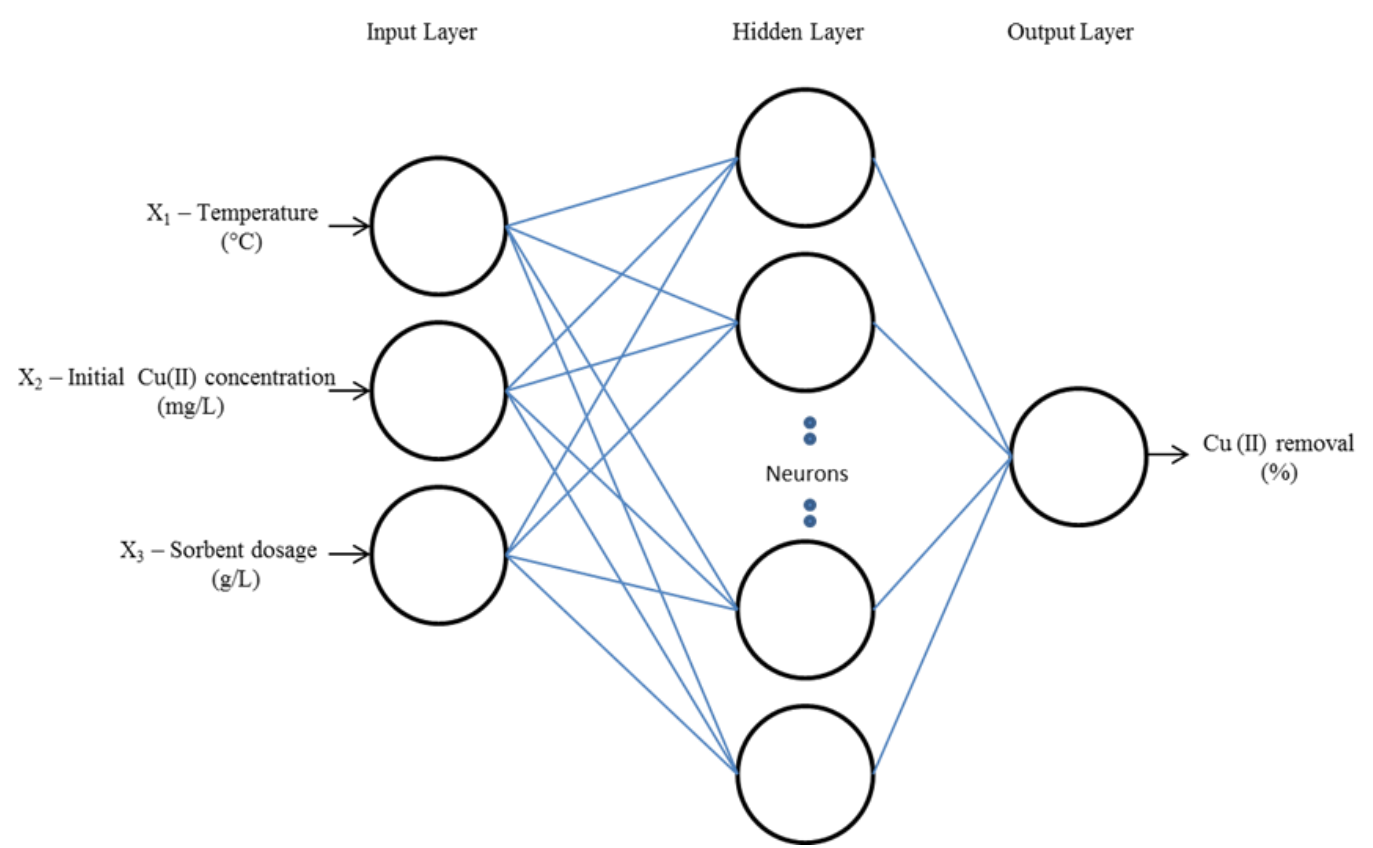

Figure 1: Architecture of the developed artificial neural network (ANN)

\subsection{Stability of the modified adsorbent}

The stability of the modified CNWs was tested at different time intervals under dry conditions and in the water matrix. For dry stability, the carboxylate content of the modified CNWs was determined using conductometric titration on the modified CNWs stored under dry conditions for different times (7, 14 and 28 days).

For the wet stability test, freeze-dried CNWs were mixed with deionized water and left for $30 \mathrm{~min}, 24 \mathrm{~h}$ and 7 days under constant shaking at a rate of $150 \mathrm{rpm}$ in an incubator before titration experiments. Next, the suspensions were freeze-dried and used for the batch experiments. Batch experiments were carried out in conical flasks by adding modified CNWs in $20 \mathrm{~mL}$ of aqueous copper solution at the same conditions The initial and final concentrations of $\mathrm{Cu}$ (II) solutions were determined using AAS. Freshly prepared modified CNWs were used as the control experiment. 


\section{Results and discussion}

\subsection{Characterisation of carboxylate group on CNWs}

The proof of the negative surface charge induced by the modification step comes from zeta potential measurements where nanoparticles with a high zeta potential (greater than $\pm 25 \mathrm{mV}$ ) are electrically stabilized while nanoparticles with low zeta potential tend to flocculate or coagulate (Saito et al., 2009). The average zeta potentials for the unmodified and modified CNWs were $-37.6 \mathrm{mV}$ and $-74.4 \mathrm{mV}$, respectively. The oxidized CNWs showed much higher negative zeta potential caused by the introduction of carboxylic acid groups at the surface of CNWs. FTIR spectra of CNWs are compared before and after modification. After modification, the presence of band near at $1730 \mathrm{~cm}^{-1}$ corresponds to the $\mathrm{C}=\mathrm{O}$ stretching frequency of carboxyl groups have been incorporated onto CNWs, indicating successful oxidation at the surface.

\subsection{Determination of carboxylate contents}

The carboxyl content of chemically modified CNWs was measured using conductivity titration method and determined to be 54 and $410 \mathrm{mmol} / \mathrm{kg}$ for the unmodified and modified CNWs respectively. The content is notably within the range what has been reported in the literature (Saito et al., 2005). Similar performance was also found for modified CNWs kept under wet or dry conditions for different time intervals. The sorbent ability for each sample did not change or reduce, which proved that CNWs are stable in water for the tested time period of up to 7 days and may be stored under dry conditions for the period time examined (up to 28 days). This showed that this functional group is permanent under the conditions tested as the groups are stable and not removed/ degraded.

A control experiment was then carried out to compare the ability of unmodified and modified $\mathrm{CNW}$ s to remove $\mathrm{Cu}(\mathrm{II})$ from the water matrix. For the same amount of sorbent dosage under similar conditions, modified CNWs were able to remove $\pm 66.75 \%$ of $\mathrm{Cu}$ (II) while the unmodified $\mathrm{CNW}$ s removed only $\pm 3.64 \%$ of $\mathrm{Cu}$ (II) from the water matrix. The adsorption capacity of these adsorbents was $14.65 \mathrm{mg} / \mathrm{g}$ and $0.59 \mathrm{mg} / \mathrm{g}$, respectively.

This is because of the carboxyl groups introduced on the CNW surface by the TEMPO-mediated oxidation process. This has been confirmed by other researchers that 
cellulose containing carboxyl will enhance the adsorption process in removing the heavy metals from the water matrix (Liu et al., 2009).

\subsection{Scoping studies}

The purpose of the scoping studies was to identify the variables and parameter ranges that influence the adsorption process and help set the boundary conditions for the $\mathrm{CCD}$. The optimum $\mathrm{pH}$ range (4-6) for the adsorption process published in the literature were considered too acidic since a $\mathrm{pH}$ below 6 will increase the competition between protons and metal ions for active sites (Reddy, 2012). Moreover, to prevent the formation of metal hydroxide precipitation at $\mathrm{pH}$ higher than 6 , it was decided that the optimum $\mathrm{pH}$ for the removal of $\mathrm{Cu}(\mathrm{II})$ ions using modified $\mathrm{CNW}$ s was at $\mathrm{pH}$. This has been confirmed by control experiments, where the optimum $\mathrm{pH}$ value for maximum removal of $\mathrm{Cu}(\mathrm{II})$ was observed at $\mathrm{pH} 6$ with $91.3 \%$ (2.04 mg/g) of $\mathrm{Cu}(\mathrm{II})$ removed, while at pH 4 only $85.5 \%$ (1.88 mg/g) Cu(II) removal was achieved.

The contact time for the adsorption process was chosen to be $30 \mathrm{~min}$ in accordance with results obtained from the scoping studies since further increase in the contact time did not show a significant change in percentage removal. From the results, it was found that the adsorption increased sharply with contact time during the first 5 min, contributing to more than $91 \%$ of $\mathrm{Cu}$ (II) removal. It then decreased slowly to reach plateau and it was observed that $30 \mathrm{~min}$ was enough to reach the adsorption equilibrium.

The adsorption of metal ions using the modified CNWs was then tested through batch experiments, keeping the contact time at $30 \mathrm{~min}$ and the $\mathrm{pH}$ at 6 while varying temperature, absorbent dose and copper ion concentration based on values used in industrial processes and environmental regulations (Thirumavalavan et al., 2010).

Control experiments were carried out to identify the most appropriate filter to ascertain that the membrane material used did not adsorb any remaining metal ions in solution. Surfactant-free cellulose acetate filters were identified as most suitable with an average adsorption of $\pm 0.8 \%$, and results corrected for this. 


\subsection{Modelling of adsorption process}

\subsubsection{RSM model}

Results for the percentage of $\mathrm{Cu}$ (II) removal were obtained by performing the batch experiments according to the CCD matrix of conditions. Table 1 shows the experimental results obtained from the experimental runs and the predicted values by the built RSM and ANN models. One of the 20 experiments, with $0.2 \mathrm{~g} / \mathrm{L}$ sorbent dosage, showed a large residual error with $10.9 \%$ for the RSM model, which influence the value of $\mathrm{R}^{2}$. Similar problems occurred but not to the same degree of error when less than $2.10 \mathrm{~g} / \mathrm{L}$ sorbent dosage was used to remove $\mathrm{Cu}(\mathrm{II})$ from the water matrix. This problem is believed to be due to the presence of adsorbed species at the surface of the cellulose nanowhiskers blocking reactive sites (Labet and Thielemans, 2011). For the higher sorbent dosage, it will not impact the adsorption process due to greater availability of reactive sites on the CNWs. Similar results were reported for other heavy metal adsorption onto biomass (Sugashini and Begum, 2013). However, from Figure 2, it still can be observed that the predicted values by the RSM model and the actual experimental data are in good agreement, with a coefficient of determination $\left(\mathrm{R}^{2}=\right.$ 0.9541). Moreover, the more reliable way to evaluate the quality of the fitted model is by application of analysis of variance (ANOVA). The significance of each term in the equation on the percentage of the adsorbed $\mathrm{Cu}$ (II) ions was validated by this statistical test.

From the 20 experiments, the adsorption capacity ( $\mathrm{mg} \mathrm{Cu}(\mathrm{II}) / \mathrm{g}$ adsorbent) was calculated (Table 1) identifying the initial $\mathrm{Cu}$ (II) concentration and sorbent dosage as the most important parameters affecting adsorption capacity. The adsorption capacities increased with increasing initial $\mathrm{Cu}(\mathrm{II})$ concentration due to the $\mathrm{Cu}(\mathrm{II})$ concentration providing driving force to overcome the mass transfer resistance. 
Table 1: Experimental ranges and levels of the independent variables

\begin{tabular}{lcccccc}
\hline \multicolumn{1}{c}{ Independent variable } & Symbols & \multicolumn{5}{c}{ Range and level } \\
\hline & & $-\alpha$ & -1 & 0 & 1 & $+\alpha$ \\
\hline $\begin{array}{l}\text { Temperature, } \mathrm{T}\left({ }^{\circ} \mathrm{C}\right) \\
\text { Initial Cu (II) ion }\end{array}$ & $\mathrm{X}_{1}$ & 6 & 9.68 & 15.5 & 21.32 & 25 \\
$\begin{array}{l}\text { concentration, } \mathrm{C}(\mathrm{mg} / \mathrm{L}) \\
\text { Sorbent dosage, } \mathrm{m}(\mathrm{g} / \mathrm{L})\end{array}$ & $\mathrm{X}_{2}$ & 10 & 19.69 & 35 & 50.31 & 60 \\
\hline
\end{tabular}

\begin{tabular}{|c|c|c|c|c|c|c|c|c|c|}
\hline Run & $\mathrm{T}$ & $\bar{C}$ & $\mathrm{~m}$ & $\bar{q}$ & & $\mathrm{Cu}(\mathrm{II}$ & removal (c & & \\
\hline Number & $\left({ }^{\circ} \mathrm{C}\right)$ & $(\mathrm{mg} / \mathrm{L})$ & $(\mathrm{g} / \mathrm{L})$ & $(\mathrm{mg} / \mathrm{g})$ & Experimental & RSM & Residual & ANN & Residual \\
\hline 1 & 21.3 & 50.31 & 2.10 & 10.63 & 44.50 & 39.35 & 5.15 & 44.75 & 0.25 \\
\hline 2 & 21.3 & 19.69 & 8.10 & 2.47 & 95.72 & 96.33 & 0.61 & 96.06 & 0.34 \\
\hline 3 & 9.7 & 19.69 & 2.10 & 6.53 & 74.81 & 68.83 & 5.98 & 74.77 & 0.04 \\
\hline 4 & 15.5 & 35.00 & 5.10 & 5.05 & 76.95 & 77.51 & 0.56 & 77.45 & 0.49 \\
\hline 5 & 15.5 & 35.00 & 5.10 & 4.95 & 76.35 & 77.51 & 1.16 & 77.45 & 1.10 \\
\hline 6 & 9.7 & 50.31 & 8.10 & 4.56 & 77.80 & 78.46 & 0.66 & 77.66 & 0.14 \\
\hline 7 & 21.3 & 19.69 & 2.10 & 5.75 & 72.54 & 67.49 & 5.05 & 70.00 & 2.54 \\
\hline 8 & 15.5 & 35.00 & 5.10 & 5.14 & 78.97 & 77.51 & 1.46 & 77.45 & 1.52 \\
\hline 9 & 15.5 & 35.00 & 5.10 & 4.78 & 75.68 & 77.51 & 1.83 & 77.45 & 1.77 \\
\hline 10 & 9.7 & 19.69 & 8.10 & 2.09 & 93.24 & 94.00 & 0.76 & 98.27 & 5.03 \\
\hline 11 & 9.7 & 50.31 & 2.10 & 9.63 & 42.93 & 37.93 & 5.00 & 42.89 & 0.03 \\
\hline 12 & 21.3 & 50.31 & 8.10 & 5.30 & 81.94 & 83.54 & 1.60 & 81.59 & 0.35 \\
\hline 13 & 6.0 & 35.00 & 5.10 & 4.77 & 74.33 & 78.09 & 3.76 & 75.18 & 0.84 \\
\hline 14 & 15.5 & 35.00 & 10.00 & 2.99 & 88.65 & 84.34 & 4.31 & 88.84 & 0.19 \\
\hline 15 & 15.5 & 35.00 & 5.10 & 4.72 & 78.08 & 77.51 & 0.57 & 77.45 & 0.63 \\
\hline 16 & 15.5 & 60.00 & 5.10 & 6.50 & 58.26 & 61.00 & 2.74 & 58.03 & 0.23 \\
\hline 17 & 25.0 & 35.00 & 5.10 & 5.07 & 78.33 & 81.14 & 2.81 & 78.15 & 0.17 \\
\hline 18 & 15.5 & 10.00 & 5.10 & 1.58 & 92.85 & 96.68 & 3.83 & 93.82 & 0.97 \\
\hline 19 & 15.5 & 35.00 & 5.10 & 5.07 & 81.20 & 77.51 & 3.69 & 77.45 & 3.75 \\
\hline 20 & 15.5 & 35.00 & 0.20 & 20.67 & 16.81 & 27.70 & 10.89 & 16.86 & 0.05 \\
\hline
\end{tabular}




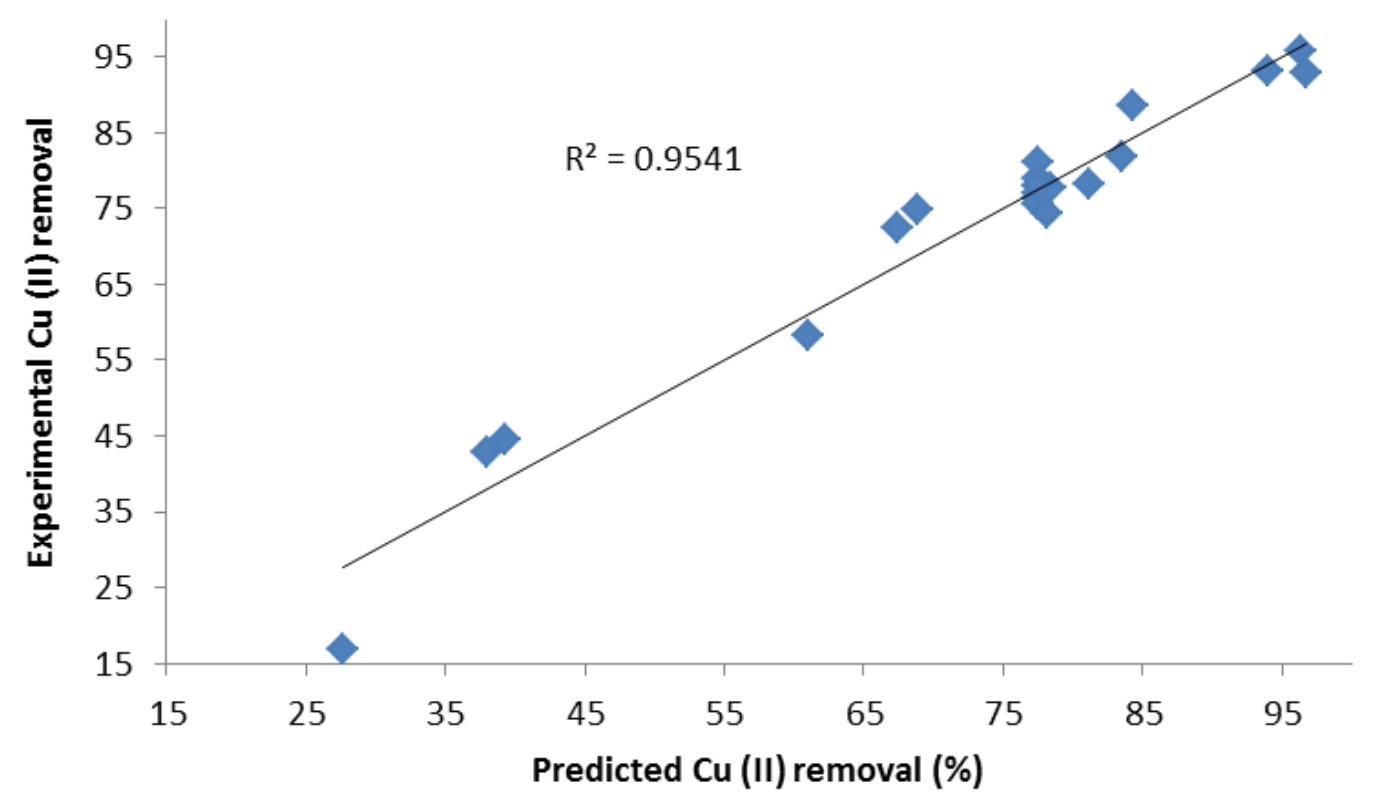

Figure 2: The experimentally obtained for $\mathrm{Cu}$ (II) removal compared to that predicted by the response surface methodology (RSM)

Remarkably, as can be seen in the Table 2, it can be shown that most of the terms in the quadratic model are statistically insignificant $(\mathrm{P}>0.05)$ for their effect on the $\mathrm{Cu}(\mathrm{II})$ percentage removal with a model F-value of 23.09.

Table 2: Regression analysis of the RSM model for the \% removal of $\mathrm{Cu}$, with the associated statistical significance of each coefficient

\begin{tabular}{lccc}
\hline Coefficient & Coefficient & $F$-Value & $P$-Value \\
\hline Constant & 77.5063 & 0.360 & \\
$\mathrm{~T}\left(\mathrm{X}_{1}\right)$ & 0.9339 & 49.810 & 0.560 \\
$\mathrm{C}\left(\mathrm{X}_{2}\right)$ & -10.9219 & 125.600 & 0.000 \\
$\mathrm{~m}\left(\mathrm{X}_{3}\right)$ & 17.3425 & 0.260 & 0.000 \\
$\mathrm{~T}^{*} \mathrm{~T}\left(\mathrm{X}_{1}^{2}\right)$ & 0.7922 & 0.100 & 0.621 \\
$\mathrm{C}^{*} \mathrm{C}\left(\mathrm{X}_{2}^{2}\right)$ & 0.5016 & 26.850 & 0.754 \\
$\mathrm{~m}^{*} \mathrm{~m}\left(\mathrm{X}_{3}^{2}\right)$ & -8.0577 & 0.120 & 0.000 \\
$\mathrm{~T}^{*} \mathrm{C}\left(\mathrm{X}_{1} \mathrm{X}_{2}\right)$ & 0.6875 & 0.210 & 0.738 \\
$\mathrm{~T}^{*} \mathrm{~m}\left(\mathrm{X}_{1} \mathrm{X}_{3}\right)$ & 0.915 & 3.690 & 0.657 \\
$\mathrm{C}^{*} \mathrm{~m}\left(\mathrm{X}_{2} \mathrm{X}_{3}\right)$ & 3.8375 & & 0.084 \\
\hline
\end{tabular}


The ANOVA of this model is presented in Table 3 and the model was assessed for its suitability by examining the lack of fit through ANOVA. From the results, the lack of fit obtained is significant due to low probability $(\mathrm{P}=0.005)$ and higher F-test value of 14.73. Thus, this results showed that the RSM model is unable to predict the removal of $\mathrm{Cu}(\mathrm{II})$ from water matrix.

Table 3: ANOVA to determine the suitability of the developed quadratic model in fitting the experimental data

\begin{tabular}{llcll}
\hline Source & Sum of squares & Degree of freedom & $F$-value & $P$-value \\
\hline Model & 6635.87 & 9 & 23.09 & 0 \\
Residual error & 319.29 & 10 & - & - \\
Lack-of-fit & 299 & 5 & 14.73 & 0.005 \\
Pure error & 20.3 & 5 & - & - \\
\hline
\end{tabular}

As can be seen from Table 2, the initial $\mathrm{Cu}$ (II) concentration and sorbent dosage, $\mathrm{X}_{2}$ and $\mathrm{X}_{3}$, have both a significant effect, while the second-order effects of sorbent dosage $\left(\mathrm{X}_{3}^{2}\right)$ on the $\mathrm{Cu}(\mathrm{II})$ percentage removal has the highest significant effect among the other second-order effects. The negative value of the main effect coefficient, initial $\mathrm{Cu}$ (II) concentration, demonstrates that $\mathrm{Cu}$ percentage removal decreases with increasing initial $\mathrm{Cu}$ (II) concentration. Plus, the negative coefficient of the second order parameters, shows a maximum value in response within selected range of the parameters, which showed that large amount of sorbent dosage will give higher removal of $\mathrm{Cu}$ (II) from the water matrix (Shojaeimehr et al., 2014).

\subsubsection{ANN model}

In this study, an ANN-based model was also developed for describing the removal of $\mathrm{Cu}$ (II) by modified CNWs. Similar to RSM modelling, the data generated through CCD were used to determine the optimal architecture of the ANN model. The total of 20 experiments was divided into three subsets comprising of training (12 data points), validation (4 data points) and testing (4 data points) points. The aim of the splitting of data into three subsets was to measure the capability of the model for the prediction of unseen experiments, which were not used for training. Thus, the overview performance of ANN model can be assessed. 
The actual and predicted percentage removal of $\mathrm{Cu}$ (II) by the ANN model is presented in Figure 3 and the coefficient of determination $\mathrm{R}^{2}$ was found to be 0.9925 , showing good agreement with the two sets of results.

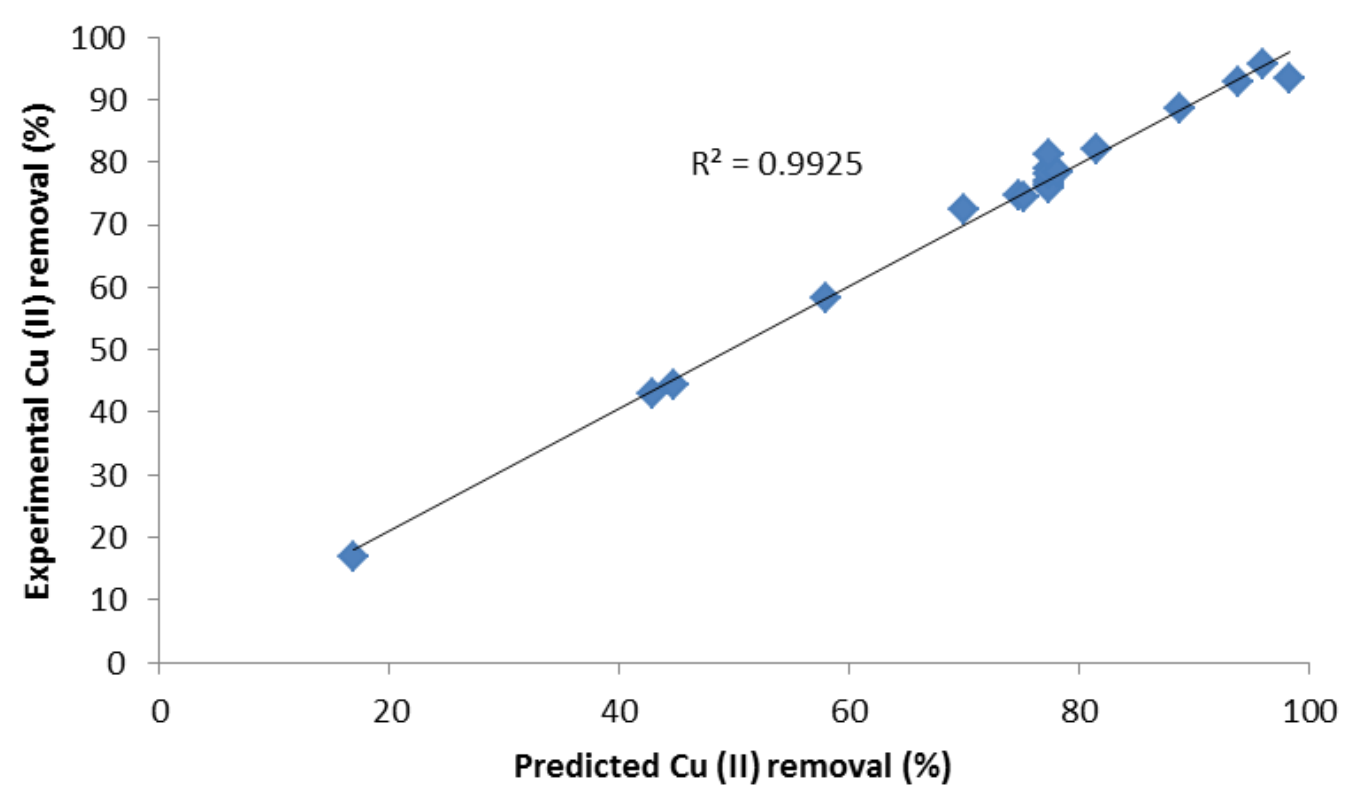

Figure 3: The experimentally obtained for $\mathrm{Cu}$ (II) removal compared to that predicted by the artificial neural network (ANN)

For better graphical interpretation of the $\mathrm{Cu}(\mathrm{II})$ adsorption process, threedimensional response surface plots were generated. Figure 4 shows the effect of the investigated parameters on the removal of $\mathrm{Cu}(\mathrm{II})$, with one of the three parameters held constant at its intermediate value $\left(15.5^{\circ} \mathrm{C}, 35 \mathrm{mg} / \mathrm{L}\right.$, or $\left.5.10 \mathrm{~g} / \mathrm{L}\right)$. Figure 4 (A) shows the response of the $\mathrm{Cu}(\mathrm{II})$ removal when varying the initial $\mathrm{Cu}(\mathrm{II})$ concentration and sorbent dosage.

Generally, ANN-based data analysis indicated that a high amount of sorbent dosage and a low initial $\mathrm{Cu}$ (II) ion concentration increased the percentage removal of $\mathrm{Cu}$ (II) from the water matrix due to availability of adsorption sites. As can been seen from Figure 4(A), the percentage removal of $\mathrm{Cu}(\mathrm{II})$ increased when raising the sorbent dosage up to $8 \mathrm{~g} / \mathrm{L}$ and then removal stayed constant with further increase of sorbent dosage above. These results are consistent with findings reported in literature (Geyikci et al., 2012). The increased in the percentage removal when the sorbent dosage 
increased is due to the concentration gradient acting as a driving force between the solute concentration and that adsorbed onto the surface of the modified CNWs.

Figure 4 (B) shows that the variation of temperature only had a slight effect on the $\mathrm{Cu}(\mathrm{II})$ removal. This indicates that higher temperature values did not damage the active sites in the sorbent or weaken the adsorptive force between the active sites of the adsorbent and $\mathrm{Cu}(\mathrm{II})$ ions significantly, at least not in the temperature range studied in this work.

Figure 4 (C) shows that the percentage removal of $\mathrm{Cu}$ (II) decreases at higher initial $\mathrm{Cu}$ (II) concentration as there will be a relative decrease of available active metal binding sites per $\mathrm{Cu}(\mathrm{II})$ ion for adsorption. At a fixed sorbent dosage, there was a decrease in the percentage removal with further increasing of the initial $\mathrm{Cu}$ (II) concentration due to the saturation of $\mathrm{CNW}$ s surface with $\mathrm{Cu}(\mathrm{II})$ ions. On the other hand, the change in temperature had no significant effect on the response over the range of temperatures investigated in this study. This result differs to other studies and likely explained due to the literature experiments being conducted under temperatures that are not realistic to a wastewater treatment environment (Bingol et al., 2012; Shojaeimehr et al., 2014). Cao et al. (2014) presented the effects of temperature $\left(10-50^{\circ} \mathrm{C}\right)$ and showed that the adsorption of $\mathrm{Cr}(\mathrm{VI})$ increased with increasing temperature even when the range was higher and unrealistic conditions to a wastewater treatment environment (Cao et al., 2014). 

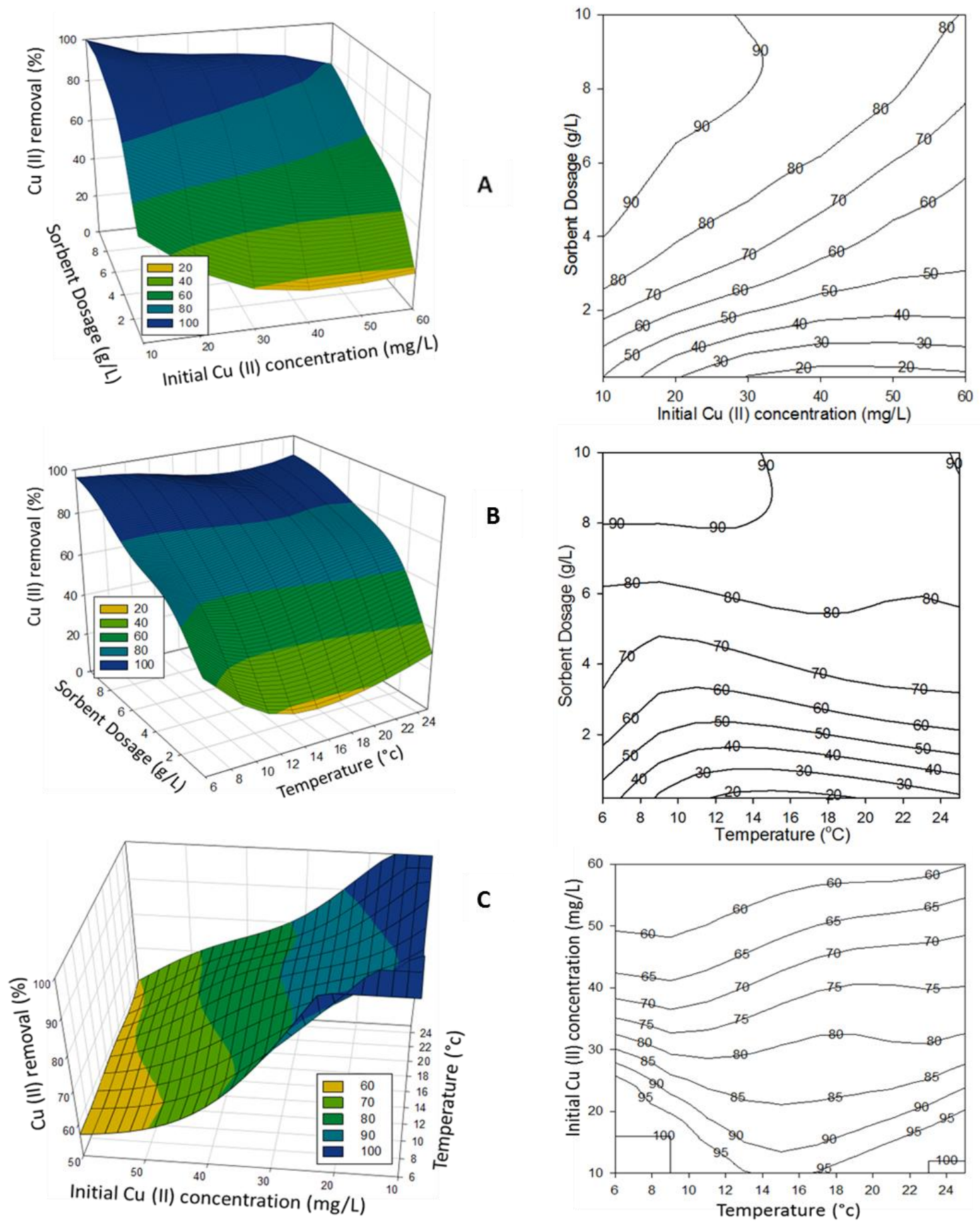

Figure 4: Surface plots (left) and corresponding contour plots (right) showing the effects of adsorption parameters on the $\mathrm{Cu}$ (II) removal as predicted by the ANN model with temperature held at constant at $15.5^{\circ} \mathrm{C}$ (A), initial $\mathrm{Cu}$ (II) concentration held at constant $35 \mathrm{mg} / \mathrm{L}$ (B), and sorbent dosage held constant at $5.10 \mathrm{~g} / \mathrm{L}$ (C). 


\subsection{Comparison of RSM and ANN}

Besides examining the poorness of the fit using ANOVA for the RSM model as determined in Section 3.4.1, the abilities of the ANN and RSM model in predicting the $\mathrm{Cu}$ (II) removal from the water matrix were statistically evaluated, in terms of the coefficient of determination $\left(\mathrm{R}^{2}\right)$, absolute average deviation (AAD), and the root mean squared error (RMSE). The AAD and RMSE are defined as follows (Geyikci et al., 2012):

$$
\begin{aligned}
& A A D=\left(\frac{1}{n} \sum_{i=1}^{n}\left(\frac{y_{p}-y_{e}}{y_{e}}\right)\right) \times 100 \\
& R M S E=\left(\frac{1}{n} \sum_{i=1}^{n}\left(y_{p}-y_{e}\right)^{2}\right)^{1 / 2}
\end{aligned}
$$

Where $\mathrm{n}$ is the number of points, $\mathrm{y}_{\mathrm{p}}$ is the predicted value, $\mathrm{y}_{\mathrm{e}}$ is the experimental value.

The AAD and RMSE for the RSM model were calculated to be $7.07 \%$ and 3.99, whilst that of the ANN model was $1.15 \%$ and 1.66 . Moreover, with the $\mathrm{R}^{2}$ for both models $\left(\mathrm{R}^{2}=0.9541\right.$ for RSM, $\mathrm{R}^{2}=0.9925$ for ANN), showed that ANN model predicts more accurately than the RSM model.

For further validation, 14 extra experiments were conducted in addition to those determined by the $\mathrm{CCD}$, consisting of combinations of experimental parameters not found in the training data set for the models. 3D scatter plots for the unseen experiments are displayed in Figure 6, and include a comparison of 3D scatter plots derived from data contained in two other studies. In general, the limited number of studies that do conduct unseen experiments tend to use a limited number and the chosen unseen experiments do not represent the system of conditions making it difficult to appropriately evaluate the predictive capability of the models. In Figure 6(C), Bingol et al. (Bingol et al., 2012) tested the validity of the models by conducting 11 new trials that are all concentrated on one side of the system whilst Ghosh et al. (Ghosh et al., 
2015), depicted in Figure 6(B), conducted 8 unseen experiments which do not represent the whole system, in order to study the validity of the RSM and ANN models.

The 14 unseen experiments undertaken in this study and illustrated in Figure 6(A) were chosen to represent parameter space both inside and outside the system, in order to give better understanding in testing the validity of the models. The actual and predicted values of the responses along with their residual values for both models are given in Table 4. The prediction abilities of the newly constructed ANN and RSM models were statistically measured, in terms of $\mathrm{R}^{2}, \mathrm{AAD}$, and RMSE. Table 5 shows the statistical comparison of both models based on the $20 \mathrm{CCD}$ and unseen experiments that represent both inside and outside of the system. From the results, it is confirmed that the ANN model predicts more accurately than the RSM model, both the original 20 CCD and 14 unseen experiments.

Although both the RSM and ANN models provided good quality predictions $\left(\mathrm{R}^{2}\right)$ for the parameters within the design range, the ANN model showed a clear superiority over the RSM model for both data fitting and estimation capabilities for the parameters that were outside of the design range (Figure 5). The results showed similar findings with other research that compared both models for removal of pollutants from a water matrix (Bingol et al., 2012; Shojaeimehr et al., 2014). Therefore, the ANN model is more flexible and predictable which allows the addition of a new set of experiment to build a new dependable model. This is because the RSM model has the limitation where it assumes only quadratic non-linear correlation whilst the ANN model overcomes this limitation since this model can inherently capture almost any complex and non-linear process (Bingol et al., 2012; Geyikci et al., 2012). 
Table 4: Validation data for 14 unseen experiments

\begin{tabular}{|c|c|c|c|c|c|c|c|c|c|c|}
\hline \multirow[b]{2}{*}{$\begin{array}{l}\text { Data } \\
\text { index }\end{array}$} & \multirow{2}{*}{ Run } & \multirow{2}{*}{$\begin{array}{l}\mathrm{T} \\
\left({ }^{\circ} \mathrm{c}\right)\end{array}$} & \multirow{2}{*}{$\begin{array}{l}\text { C } \\
(\mathrm{mg} / \mathrm{L})\end{array}$} & \multirow{2}{*}{$\begin{array}{l}\mathrm{m} \\
(\mathrm{g} / \mathrm{L})\end{array}$} & \multirow{2}{*}{$\begin{array}{l}\text { Adsorption } \\
\text { capacity } \\
(\mathrm{mg} / \mathrm{g})\end{array}$} & \multirow{2}{*}{$\begin{array}{l}\mathrm{Cu}(\mathrm{II}) \\
\text { removal } \\
(\%)\end{array}$} & \multicolumn{2}{|l|}{ ANN } & \multicolumn{2}{|l|}{ RSM } \\
\hline & & & & & & & Predicted & Residual & Predicted & Residual \\
\hline \multirow{7}{*}{ 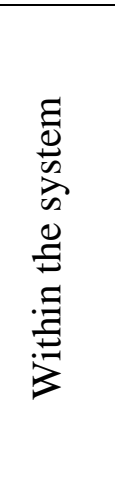 } & 1 & 21.3 & 50.31 & 5.1 & 5.27 & 62.21 & 66.82 & -4.61 & 69.35 & -7.14 \\
\hline & 2 & 9.7 & 19.69 & 5.1 & 3.17 & 84.06 & 92.57 & -8.51 & 89.45 & -5.39 \\
\hline & 3 & 15.5 & 35.00 & 8.1 & 4.23 & 82.39 & 89.09 & -6.7 & 86.72 & -4.33 \\
\hline & 4 & 18 & 55.00 & 8.1 & 4.76 & 74.19 & 77.83 & -3.64 & 79.56 & -5.37 \\
\hline & 5 & 10 & 55.00 & 4.0 & 5.75 & 60.41 & 53.96 & 6.45 & 53.97 & 6.44 \\
\hline & 6 & 20 & 35.00 & 9.5 & 1.23 & 82.64 & 86.87 & -4.23 & 87.77 & -5.13 \\
\hline & 7 & 20 & 15.00 & 5.1 & 3.10 & 88.31 & 93.27 & -4.96 & 92.67 & -4.36 \\
\hline \multirow{7}{*}{ 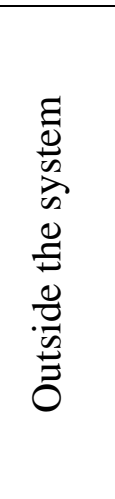 } & 8 & 6 & 10.00 & 8.1 & 1.13 & 91.37 & 100 & -8.63 & 100 & -8.63 \\
\hline & 9 & 25 & 60.00 & 8.1 & 5.57 & 70.43 & 79.34 & -8.91 & 83.33 & -12.9 \\
\hline & 10 & 25 & 60.00 & 4.0 & 9.26 & 57.2 & 52.72 & 4.48 & 56.01 & 1.19 \\
\hline & 11 & 10 & 10.00 & 4.0 & 1.84 & 92.23 & 100 & -7.77 & 92.73 & -0.50 \\
\hline & 12 & 6 & 35.00 & 2.1 & 5.58 & 55.75 & 63.49 & -7.74 & 54.14 & 1.61 \\
\hline & 13 & 6 & 20.00 & 2.1 & 3.21 & 86.24 & 88.62 & -2.38 & 70.22 & 16.02 \\
\hline & 14 & 10 & 10.00 & 2.1 & 2.32 & 90.02 & 94.3 & -4.28 & 79.3 & 10.72 \\
\hline
\end{tabular}

Table 5: Comparison of the predictive abilities of RSM and ANN model

\begin{tabular}{lcccccc}
\hline \multirow{2}{*}{ Data index } & \multicolumn{2}{c}{ Correlation coefficient $\left(\mathrm{R}^{2}\right)$} & \multicolumn{2}{c}{ AAD $(\%)$} & \multicolumn{2}{c}{ RMSE } \\
\cline { 2 - 7 } & ANN & RSM & ANN & RSM & ANN & RSM \\
\hline 20 CCD & 0.9925 & 0.9541 & 1.15 & 7.07 & 1.66 & 4.00 \\
14 unseen & 0.9357 & 0.7324 & 7.98 & 8.28 & 6.29 & 7.70 \\
7 Inside & 0.9530 & 0.9162 & 7.43 & 7.46 & 5.81 & 9.39 \\
7 Outside & 0.9395 & 0.6783 & 8.54 & 9.11 & 6.74 & 9.39 \\
\hline
\end{tabular}




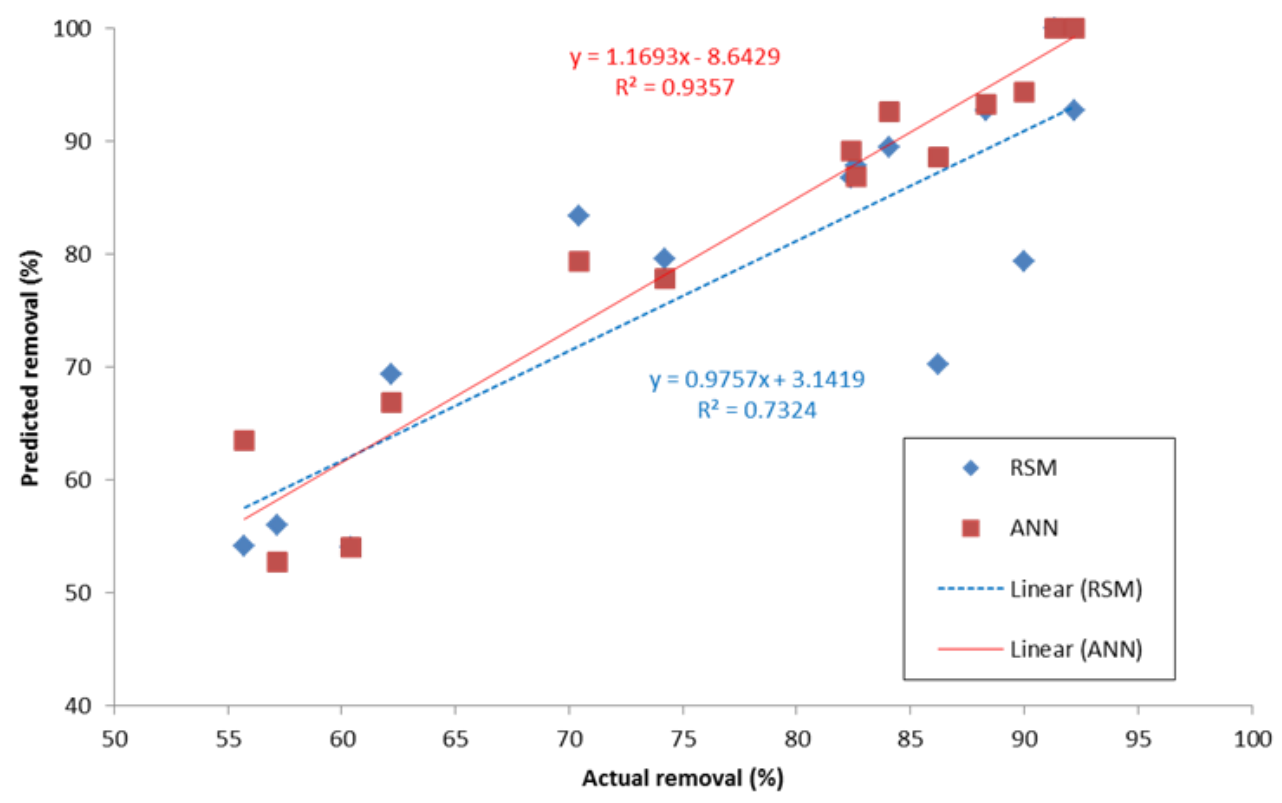

Figure 5: Comparison of the experimental and predicted results for unseen experiments between RSM and ANN 


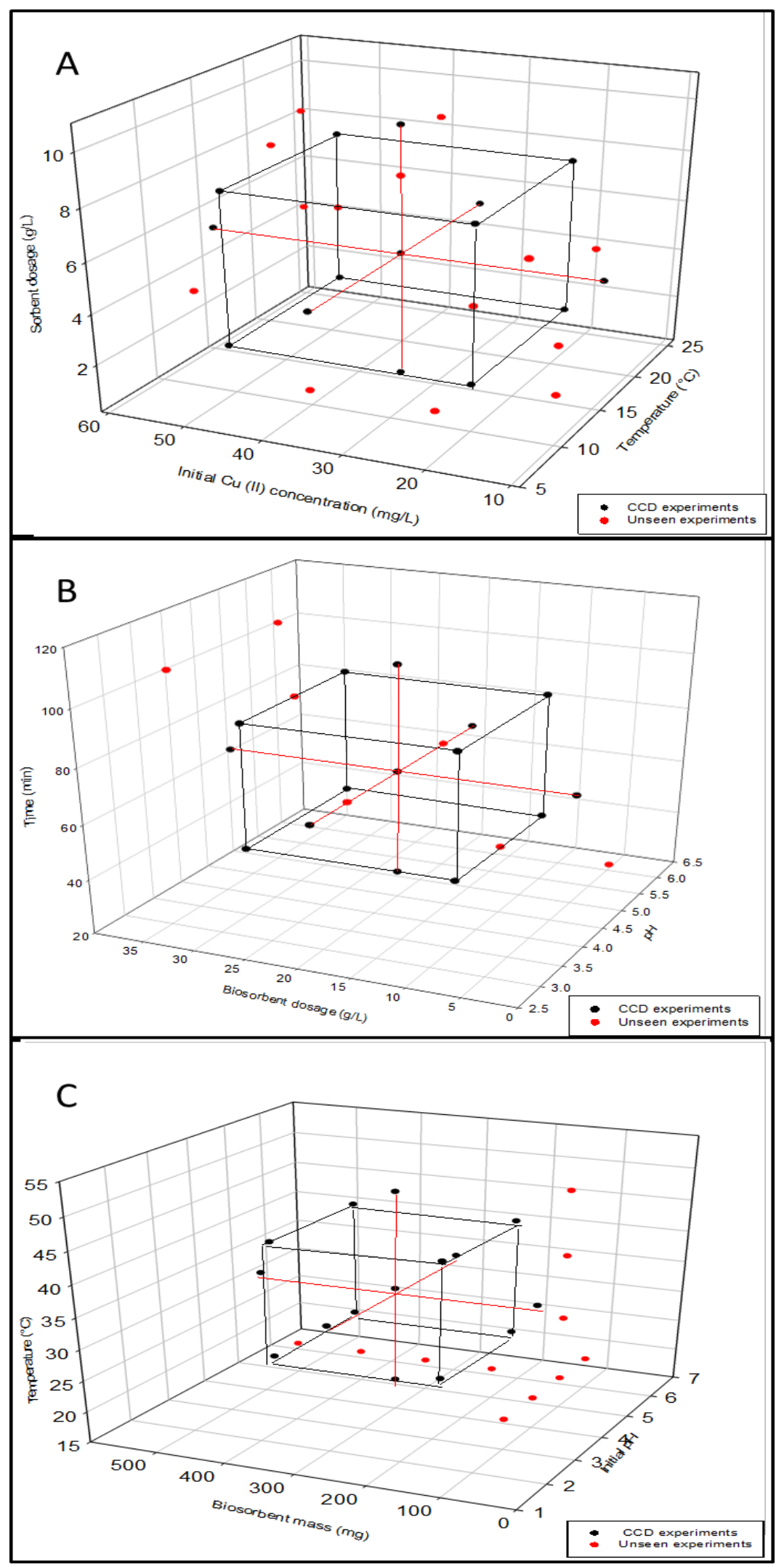

Figure 6: 3D scatter plots showing comparison of the CCD with unseen experiments within the systems (A) for this work (B) (Ghosh et al., 2015) (C) (Bingol et al., 2012). 


\subsection{Adsorption isotherm}

In order to understand the behaviour of adsorbent, two common adsorption isotherms (Langmuir and Freundlich) were used to evaluate the adsorption system design and to describe the adsorption capacities of the modified adsorbent (Shojaeimehr et al., 2014). These isotherms were expressed in linear form as:

$$
\text { Langmuir: } \frac{C_{e}}{q_{e}}=\frac{C_{e}}{q_{m}}+\frac{1}{K_{L} q_{m}}
$$

Where $\mathrm{q}_{\mathrm{e}}(\mathrm{mg} / \mathrm{g})$ is the equilibrium amount of $\mathrm{Cu}(\mathrm{II})$ adsorbed per unit mass of sorbent, $\mathrm{q}_{\mathrm{m}}(\mathrm{mg} / \mathrm{g})$ is the maximum $\mathrm{Cu}(\mathrm{II})$ ions adsorption capacity to form a complete monolayer on the surface bound and $\mathrm{K}_{\mathrm{L}}(1 / \mathrm{mg})$ is the Langmuir constant which related to the affinity of the binding sites.

$$
\text { Freundlich: } \log q_{e}=\log K_{f}+\left(\frac{1}{n}\right) \log C_{e}
$$

Where $\mathrm{K}_{\mathrm{f}}$ and $\mathrm{n}_{\mathrm{f}}$ are the Freundlich constants that indicates adsorption capacity and adsorption intensity, respectively. The Freundlich isotherm indicates the heterogeneous surface.

From the results, the coefficient of determination $\left(\mathrm{R}^{2}\right)$ showed that the Langmuir isotherm $\left(R^{2}=0.9998\right)$ had a better correlation than the Freundlich isotherm $\left(R^{2}=\right.$ 0.9461), which indicated the homogeneous distribution of active sites on the adsorbent surface. The maximum monolayer adsorption capacity as obtained from the Langmuir isotherm was found as $14.65 \mathrm{mg} / \mathrm{g}$, and $\mathrm{K}_{\mathrm{L}}$ was $1.4025 \mathrm{~L} / \mathrm{mg}$. Moreover, the $\mathrm{n}_{\mathrm{f}}$ value from the Freundlich isotherm was $5.19(1<\mathrm{n}<10)$ indicating adsorption is favourable for the studied concentration range (Singh et al., 2010).

In addition, the comparison of $\mathrm{Cu}(\mathrm{II})$ sorption performance is better based on a complete $\mathrm{Cu}$ (II) sorption isotherm curve . Therefore, the $\mathrm{q}_{\mathrm{m}}$ value which was obtained from the Langmuir isotherm has been compared with other sorbents reported in literature based on their maximum adsorption capacity of $\mathrm{Cu}(\mathrm{II})$ ions (Table 6) (Calero et al., 2011). It is important to emphasize that a direct comparison of the $\mathrm{q}_{\mathrm{m}}$ from this study with $\mathrm{q}_{\mathrm{m}}$ of other sorbents is challenging due to experimental conditions not being comparable. Although the reported $\mathrm{Cu}$ adsorption capacity of modified CNWs was 
relatively smaller than some other adsorbents in other studies, the experimental conditions in this study were informed by conditions in the wastewater treatment process. For example, one of the important factors affecting adsorption capacities is the $\mathrm{pH}$ of the $\mathrm{Cu}(\mathrm{II})$ in water. However, other studies commonly (Table 6) commonly evaluate in the $\mathrm{pH}$ range 4.0-5.0, which as an acidic environment not representative of the actual conditions in the WWTP.

Table 6: Comparison of maximum adsorption capacities of $\mathrm{Cu}(\mathrm{II})$ ions by different adsorbents

\begin{tabular}{|c|c|c|c|c|c|c|}
\hline \multirow[b]{2}{*}{ Adsorbents } & \multicolumn{4}{|c|}{ Experimental conditions } & \multirow[b]{2}{*}{$\begin{array}{l}\mathrm{q}_{\mathrm{m}} \\
(\mathrm{mg} / \mathrm{g})\end{array}$} & \multirow[b]{2}{*}{ References } \\
\hline & $\mathrm{pH}$ & $\begin{array}{l}\mathrm{T} \\
\left({ }^{\circ} \mathrm{C}\right)\end{array}$ & $\begin{array}{l}\mathrm{Ci} \\
(\mathrm{mg} / \mathrm{L})\end{array}$ & $\begin{array}{l}\text { Time } \\
(\min )\end{array}$ & & \\
\hline Modified CNWs & 6 & 10 & $10-60$ & 30 & 14.65 & This study \\
\hline Cotton stalks & 3 & 25 & $20-200$ & 30 & 4.0 & Nada et al. (2006) \\
\hline Olive pomace & 6.5 & 20 & $50-200$ & 60 & $1.0-5.0$ & $\begin{array}{l}\text { Pagnanelli et al. } \\
\text { (2003) }\end{array}$ \\
\hline $\begin{array}{l}\text { Cellulose graft } \\
\text { polymers }\end{array}$ & 4 & 20 & 200 & 300 & 17.16 & Guclu et al. (2003) \\
\hline $\begin{array}{l}\text { Starch-graft-acrylic } \\
\text { acid copolymers }\end{array}$ & 4 & 20 & 200 & 300 & 16.52 & $\begin{array}{l}\text { Keles and Guclu } \\
\text { (2006) }\end{array}$ \\
\hline $\begin{array}{l}\text { Granular activated } \\
\text { carbon }\end{array}$ & 5 & 30 & a & $\mathrm{a}$ & 5.08 & An et al. (2001) \\
\hline $\begin{array}{l}\text { Commercial resins } \\
\text { (Duolite GT-73) }\end{array}$ & 5 & $a$ & a & $\mathrm{a}$ & 61.63 & $\begin{array}{l}\text { Vaughan et al. } \\
\text { (2001) }\end{array}$ \\
\hline
\end{tabular}

${ }^{\mathrm{a}}$ : not reported 


\subsection{Adsorption kinetics}

The prediction of adsorption rate is important in providing the necessary information for the design of the adsorption system. Two kinetic models which are Lagergren's pseudo-first order and pseudo-second order model, were applied to experimental data in order to clarify the adsorption kinetics of $\mathrm{Cu}$ (II) onto modified CNWs. The linear forms of the pseudo-first-order and second-order rate equation by Lagergren are given as (Sarı and Tuzen, 2009):

$$
\begin{gathered}
\log \left(q_{e}-q_{t}\right)=\log q_{e}-\frac{k_{1}}{2.303} t \\
\frac{t}{q_{t}}=\left(\frac{1}{q_{e}}\right) t+\frac{1}{k_{2} q_{e}^{2}}
\end{gathered}
$$

Where $\mathrm{q}_{\mathrm{t}}$ and $\mathrm{q}_{\mathrm{e}}(\mathrm{mg} / \mathrm{g})$ are the amounts of the metal ions adsorbed at time (min) and at equilibrium, respectively. $\mathrm{k}_{1}$ and $\mathrm{k}_{2}\left(\mathrm{~min}^{-1}\right)$ is the Lagergren rate constant for first and second-order equation, respectively. The adsorption rate $\left(\mathrm{k}_{1}\right)$ can be determined by plotting $\log \left(\mathrm{q}_{\mathrm{e}}-\mathrm{q}_{\mathrm{t}}\right)$ against $\mathrm{t}$ while a plot of $\mathrm{t} / \mathrm{q}_{\mathrm{t}}$ versus $\mathrm{t}$ is used for second order kinetic model and $\mathrm{k}_{2}$ was found from the slop of the plot.

The kinetics parameters obtained from both models were presented in Table 7. From the results, it can be concluded from the coefficients of determination $\left(\mathrm{R}^{2}=1.000\right)$ that the adsorption mechanism of $\mathrm{Cu}$ (II) onto modified CNWs follow the pseudo second order kinetic model. Moreover, the calculated $\mathrm{q}_{\mathrm{e}}$ value was in good agreement with experimental $\mathrm{q}_{\mathrm{e}}$ for the pseudo second order kinetic model. This model predicts the behaviour over the whole range of adsorption and is in agreement with chemical sorption being the rate controlling step. Similar results where the adsorption mechanism follow the pseudo second order kinetic model were reported by other researchers regarding the adsorption of $\mathrm{Cu}(\mathrm{II})$ onto the different adsorbents (Mata et al., 2008; Ofomaja et al., 2010). 
Table 7: Adsorption kinetic parameters of $\mathrm{Cu}(\mathrm{II})$ onto modified CNWs

\begin{tabular}{lll}
\hline Kinetic equation and parameter & \multicolumn{2}{c}{$\mathbf{C u}(\mathbf{I I})$} \\
\hline Experimental & 10.0 & 60.0 \\
$\mathrm{C}_{\mathrm{o}}(\mathrm{mg} / \mathrm{L})$ & 1.91 & 9.19 \\
$\mathrm{q}_{\mathrm{e}}(\mathrm{mg} / \mathrm{g})$ & & \\
First-order kinetic equation & 0.0207 & 0.0230 \\
$\mathrm{k}_{1}\left(\mathrm{~min}^{-1}\right)$ & 0.3502 & 4.1468 \\
$\mathrm{q}_{1}(\mathrm{mg} / \mathrm{g})$ & 0.7863 & 0.8872 \\
$\mathrm{R}^{2}$ & & \\
$\mathrm{Second}^{2}$ & & \\
$\mathrm{k}_{2}(\mathrm{~g} / \mathrm{mg}$ min $)$ & 0.2993 & 0.0191 \\
$\mathrm{q}_{2}(\mathrm{mg} / \mathrm{g})$ & 1.91 & 9.35 \\
$\mathrm{R}^{2}$ & 1.0000 & 0.9996 \\
\hline
\end{tabular}

\section{Conclusion}

In this study, chemically modified $\mathrm{CNW}$ sere effective in removing $\mathrm{Cu}$ (II) from the water matrix, offering the potential to be an abundant and inexpensive available adsorbent and suitable alternative to expensive adsorbents. Carboxyl contents of the modified CNWs were determined to be $410 \mathrm{mmol} / \mathrm{kg}$ and the zeta potential of this adsorbent dispersed in water was approximately $-74.4 \mathrm{mV}$. The adsorption capacity of modified and unmodified CNWs was found to be $14.65 \mathrm{mg} / \mathrm{g}$ and $0.59 \mathrm{mg} / \mathrm{g}$, respectively. These results indicated that the modification step has been successfully modified the nanoparticle surface. Moreover, RSM and ANN models were used to understand the operational conditions for the removal of $\mathrm{Cu}(\mathrm{II})$ using the modified CNWs. To test the predictive capability of both models, unseen experiments not used in developing the RSM and ANN models were chosen to represent both inside and outside the system. The performance of both models, which were statistically evaluated, indicated that ANN has better superior capability than RSM model. From isotherm and kinetics study, it was observed that the adsorption process followed Langmuir adsorption isotherm and pseudo-second-order kinetics. 


\section{Acknowledgements}

The authors (Hazren Hamid and Youla Jenidi) would like to acknowledge the support of Government of Malaysia for a scholarship from the Majlis Amanah Rakyat (MARA) and University of Nottingham Dean of Engineering Research Scholarship for International Excellence respectively. Wim Thielemans thanks Research FoundationFlanders (FWO) for financial support under the Odysseus program (grant G.0C60.13N) and KU Leuven for grant OT/14/072. Rachel Gomes would like to acknowledge The Leverhulme Trust for MASS - Modelling and Analytics for a Sustainable Society (Water, Energy and Food Nexus). 


\section{References}

An, H.K., Park, B.Y., Kim, D.S., 2001. Crab shell for the removal of heavy metals from aqueous solution. Water Res. 35, 3551-3556.

Anupam, K., Dutta, S., Bhattacharjee, C., Datta, S., 2011. Adsorptive removal of chromium (VI) from aqueous solution over powdered activated carbon: optimisation through response surface methodology. Chem. Eng. J. 173, 135-143.

Ashraf, M.A., Mahmood, K., Wajid, A., Maah, M.J., Yusoff, I., 2011. Study of low cost biosorbent for biosorption of heavy metals, in: Wu, K.J. (Ed.), Food Engineering and Biotechnology, pp. 60-68.

Bingol, D., Hercan, M., Elevli, S., Kilic, E., 2012. Comparison of the results of response surface methodology and artificial neural network for the biosorption of lead using black cumin. Bioresour. Technol. 112, 111-115.

Burton, F., Tchobanoglous, G., Tsuchihashi, R., Stensel, H.D., Metcalf, Eddy, I., 2013. Wastewater Engineering: Treatment and Resource Recovery. McGraw-Hill Education.

Calero, M., Blazquez, G., Martin-Lara, M.A., 2011. Kinetic modeling of the biosorption of Lead(II) from aqueous solutions by solid waste resulting from the olive oil production. J. Chem. Eng. Data 56, 3053-3060.

Cao, J., Wu, Y., Jin, Y., Yilihan, P., Huang, W., 2014. Response surface methodology approach for optimization of the removal of chromium(VI) by NH2-MCM-41. J. Taiwan Inst. Chem. Eng. 45, 860-868.

Eyley, S., Thielemans, W., 2014. Surface modification of cellulose nanocrystals. Nanoscale 6, 7764-7779.

Gavrilescu, M., 2004. Removal of heavy metals from the environment by biosorption. Eng. Life Sci. 4, 219-232.

Geyikci, F., Kilic, E., Coruh, S., Elevli, S., 2012. Modelling of lead adsorption from industrial sludge leachate on red mud by using RSM and ANN. Chem. Eng. J. 183, 53-59.

Ghosh, A., Das, P., Sinha, K., 2015. Modeling of biosorption of Cu(II) by alkalimodified spent tea leaves using response surface methodology (RSM) and artificial neural network (ANN). Appl. Water Sci. 5, 191-199.

Guclu, G., Gurdag, G., Ozgumus, S., 2003. Competitive removal of heavy metal ions by cellulose graft copolymers. J. Appl. Polym. Sci. 90, 2034-2039.

Habibi, Y., Chanzy, H., Vignon, M.R., 2006. TEMPO-mediated surface oxidation of cellulose whiskers. Cellulose 13, 679-687.

Hanaki, K., 2008. Urban Environmental Management and Technology. Springer Japan.

Isobe, N., Chen, X., Kim, U.J., Kimura, S., Wada, M., Saito, T., Isogai, A., 2013. TEMPO-oxidized cellulose hydrogel as a high-capacity and reusable heavy metal ion adsorbent. J. Hazard. Mater. 260, 195-201.

Keles, S., Guclu, G., 2006. Competitive removal of heavy metal ions by starch-graftacrylic acid copolymers. Polym.Plast. Technol. Eng. 45, 365-371.

Labet, M., Thielemans, W., 2011. Improving the reproducibility of chemical reactions on the surface of cellulose nanocrystals: ROP of epsilon-caprolactone as a case study. Cellulose 18, 607-617.

Liu, F., Luo, X., Lin, X., Liang, L., Chen, Y., 2009. Removal of copper and lead from aqueous solution by carboxylic acid functionalized deacetylated konjac glucomannan. J. Hazard. Mater. 171, 802-808. 
Mata, Y.N., Blazquez, M.L., Ballester, A., Gonzalez, F., Munoz, J.A., 2008. Characterization of the biosorption of cadmium, lead and copper with the brown alga Fucus vesiculosus. J. Hazard. Mater. 158, 316-323.

Nada, A.M.A., El-Wakil, N.A., Hassan, M.L., Adel, A.M., 2006. Differential adsorption of heavy metal ions by cotton stalk cation-exchangers containing multiple functional groups. J. Appl. Polym. Sci. 101, 4124-4132.

O'Connell, D.W., Birkinshaw, C., O'Dwyer, T.F., 2008a. Heavy metal adsorbents prepared from the modification of cellulose: a review. Bioresour. Technol. 99, 67096724.

O'Connell, D.W., Birkinshaw, C., O'Dwyer, T.F., 2008b. Removal of Copper, Nickel and Lead from wastewater using a modified cellulose material: A Comparison, in: Zamorano, M., Brebbia, C.A., Kungolos, A., Popov, V., Itoh, H. (Eds.), Waste Management and the Environment Iv, pp. 809-818.

Ofomaja, A.E., Unuabonah, E.I., Oladoja, N.A., 2010. Competitive modeling for the biosorptive removal of copper and lead ions from aqueous solution by Mansonia wood sawdust. Bioresour. Technol. 101, 3844-3852.

Oguz, E., Ersoy, M., 2010. Removal of $\mathrm{Cu}$ (II) from aqueous solution by adsorption in a fixed bed column and Neural Network Modelling. Chem. Eng. J. 164, 56-62.

Pagnanelli, F., Mainelli, S., Vegliò, F., Toro, L., 2003. Heavy metal removal by olive pomace: biosorbent characterisation and equilibrium modelling. Chem. Eng. Sci. 58, $4709-4717$.

Pilkington, J.L., Preston, C., Gomes, R.L., 2014. Comparison of response surface methodology (RSM) and artificial neural networks (ANN) towards efficient extraction of artemisinin from Artemisia annua. Ind. Crops. Prod. 58, 15-24.

Reddy, D.H.K., Seshaiah, K..,Reddy, A. V. R..,Lee, S. M., 2012. Optimization of $\mathrm{Cd}(\mathrm{II}), \mathrm{Cu}(\mathrm{II})$ and $\mathrm{Ni}(\mathrm{II})$ biosorption by chemically modified Moringa oleifera leaves powder. Carbohydr. Polym. 88, 1077-1086.

Sahan, T., Ceylan, H., Sahiner, N., Aktas, N., 2010. Optimization of removal conditions of copper ions from aqueous solutions by Trametes versicolor. Bioresour. Technol. 101, 4520-4526.

Saito, T., Hirota, M., Tamura, N., Kimura, S., Fukuzumi, H., Heux, L., Isogai, A., 2009. Individualization of nano-sized plant cellulose fibrils by direct surface carboxylation using TEMPO catalyst under neutral conditions. Biomacromolecules 10, 1992-1996.

Saito, T., Isogai, A., 2004. TEMPO-mediated oxidation of native cellulose: the effect of oxidation conditions on chemical and crystal structures of the water-insoluble fractions. Biomacromolecules 5, 1983-1989.

Saito, T., Shibata, I., Isogai, A., Suguri, N., Sumikawa, N., 2005. Distribution of carboxylate groups introduced into cotton linters by the TEMPO-mediated oxidation. Carbohydr. Polym. 61, 414-419.

Sar1, A., Tuzen, M., 2009. Kinetic and equilibrium studies of biosorption of $\mathrm{Pb}(\mathrm{II})$ and $\mathrm{Cd}(\mathrm{II})$ from aqueous solution by macrofungus (Amanita rubescens) biomass. J. Hazard. Mater. 164, 1004-1011.

Savic, I.M., Stojiljkovic, S.T., Stojanovic, S.B., Moder, K., 2012. Modeling and optimization of $\mathrm{Fe}$ (III) adsorption from water using bentonite clay: comparison of central composite design and artificial neural network. Chem. Eng. Technol. 35, 2007-2014.

Shanmugaprakash, M., Sivakumar, V., 2013. Development of experimental design approach and ANN-based models for determination of $\mathrm{Cr}(\mathrm{VI})$ ions uptake rate from 
aqueous solution onto the solid biodiesel waste residue. Bioresour. Technol. 148, 550-559.

Shojaeimehr, T., Rahimpour, F., Khadivi, M.A., Sadeghi, M., 2014. A modeling study by response surface methodology (RSM) and artificial neural network (ANN) on $\mathrm{Cu} 2+$ adsorption optimization using light expended clay aggregate (LECA). J. Ind. Eng. Chem. 20, 870-880.

Singh, R., Chadetrik, R., Kumar, R., Bishnoi, K., Bhatia, D., Kumar, A., Bishnoi, N.R., Singh, N., 2010. Biosorption optimization of lead(II), cadmium(II) and copper(II) using response surface methodology and applicability in isotherms and thermodynamics modeling. J. Hazard. Mater. 174, 623-634.

Sugashini, S., Begum, K.M.M.S., 2013. Optimization using central composite design (CCD) for the biosorption of $\mathrm{Cr}(\mathrm{VI})$ ions by cross linked chitosan carbonized rice husk (CCACR). Clean Technol. Environ. Policy 15, 293-302.

Svecova, L., Spanelova, M., Kubal, M., Guibal, E., 2006. Cadmium, lead and mercury biosorption on waste fungal biomass issued from fermentation industry. 1. Equilibrium studies. Sep. Purif. Technol. 52, 142-153.

Thirumavalavan, M., Lai, Y.L., Lin, L.C., Lee, J.F., 2010. Cellulose-based native and surface modified fruit peels for the adsorption of heavy metal ions from aqueous solution: langmuir adsorption isotherms. J. Chem. Eng. Data 55, 1186-1192.

Tovar Gomez, R., Moreno Virgen, M.R., Dena Aguilar, J.A., Hernandez Montoya, V., Bonilla Petriciolet, A., Montes Moran, M.A., 2013. Modeling of fixed-bed adsorption of fluoride on bone char using a hybrid neural network approach. Chem. Eng. J. 228, 1098-1109.

Turan, N.G., Mesci, B., Ozgonenel, O., 2013. Response surface modeling of $\mathrm{Cu}(\mathrm{II})$ removal from electroplating waste by adsorption: application of BoxBehnken experimental design. Clean-Soil Air Water 41, 304-312.

U.S. Public Health, Toxiocological Profile for Pyridine, 1992, Agency for Toxic Substances and Disease Registry U.S. Public Health Service.

Vaughan, T., Seo, C.W., Marshall, W.E., 2001. Removal of selected metal ions from aqueous solution using modified corncobs. Bioresour. Technol. 78, 133-139.

Wang, S., Wei, M., Huang, Y., 2013. Biosorption of multifold toxic heavy metal ions from aqueous water onto food residue eggshell membrane functionalized with ammonium thioglycolate. J. Agric. Food. Chem. 61, 4988-4996.

Witek-Krowiak, A., Chojnacka, K., Podstawczyk, D., Dawiec, A., Pokomeda, K., 2014. Application of response surface methodology and artificial neural network methods in modelling and optimization of biosorption process. Bioresour. Technol. 160, 150160.

Xu, L., Yao, Q., Deng, J., Han, Z., Zhang, Y., Fu, Y., Huber, G.W., Guo, Q., 2015. Renewable N-heterocycles production by thermocatalytic conversion and ammonization of biomass over ZSM-5. ACS Sustain Chem. Eng. 3, 2890-2899.

Yu, X., Tong, S., Ge, M., Wu, L., Zuo, J., Cao, C., Song, W., 2013. Adsorption of heavy metal ions from aqueous solution by carboxylated cellulose nanocrystals. J. Environ. Sci. 25, 933-943.

Zhu, H., Jia, Y., Wu, X., Wang, H., 2009. Removal of arsenic from water by supported nano zero-valent iron on activated carbon. J. Hazard. Mater. 172, 1591-1596.

Zolgharnein, J., Shahmoradi, A., Ghasemi, J.B., 2013. Comparative study of BoxBehnken, central composite, and Doehlert matrix for multivariate optimization of $\mathrm{Pb}$ (II) adsorption onto Robinia tree leaves. J. Chemom. 27, 12-20. 
